\title{
Impact of Yoga on Quality of Life (QOL) of Dental Professionals
}

\author{
Meenakshi Verma ${ }^{1}$, Deepak Langade ${ }^{2 *}$, Ashish Jain ${ }^{3}$, Prajakta Rao ${ }^{4}$ and Rahul Rao ${ }^{5}$ \\ ${ }^{1}$ Professor of Conservative Dentistry and Endodontics, Bharati Vidyapeeth Deemed University Dental College and Hospital, Faculty, Sri Sri Institute of \\ Advanced Research (SSIAR), India \\ ${ }^{2}$ Professor \& Head, Department of Pharmacology, DY Patil University School of Medicine, India \\ ${ }^{3}$ Professor \& Head Department of Conservative Dentistry and Endodontics, Bharati Vidyapeeth Deemed University Dental College and Hospital, India \\ ${ }^{4}$ Professor of Periodontology, Bharati Vidyapeeth Deemed University Dental College and Hospital, India \\ ${ }^{5}$ Professor of Conservative Dentistry and Endodontics, Bharati Vidyapeeth Deemed University Dental College and Hospital, India
}

Submission: June 26, 2017; Published: August 21, 2017

*Corresponding author: Deepak Langade, Professor \& Head, Department of Pharmacology, DY Patil University School of Medicine, Navi Mumbai, Maharashtra, India, Tel: +91 993-055-0009; Email: drdgl@hotmail.com

\begin{abstract}
Unprecedented scientific development in recent decades have led to worsening of quality of life (QOL) due to stress, functional disorders, unrest and psychological disturbances. QOL questionnaire is a standard tool in research to assess the usefulness of interventions on QOL. We observed the effect of yoga consisting of warm-ups, loosening exercises, Asanas, Pranayama, relaxation techniques and meditation on the QOL in dental professionals at a teaching dental institution in India. Our objective was to assess whether a 6-weeks integrated yoga approach helps improve the QOL in dental professionals. Twenty dental professionals (7 male/13 female) with mean age 39.45 were trained using a 45 -minute module consisting of warm-ups, loosening exercises, Asanas, Pranayama, relaxation techniques and meditation. All participants attended 20 sessions over a 6-week period. A 26-item WHO QOL-BREF questionnaire was used to assess the QOL in 5 domains (global, physical, psychological, social and environmental). The change in the scores from baseline were analyzed using Wilcoxon sign rank test and the mean scores for total QOL-BREF scores were also compared for differences using paired ' $t$ ' test. The improvement in the QOL after a 6-week yoga sessions are discussed in the results. Integrated approach of yoga at workplace improves the QOL in dental professionals especially in physical domain.
\end{abstract}

Keywords: Yoga; Quality of life; WHOQOL-BREF; Dentist

Abbreviations: aMBI: abbreviated Maslach Burnout Inventory; BCSQ-12: Burnout Clinical Subtype Questionnaire; CKD: Chronic Kidney Disease; QOL: Quality of Life; WHOQOL-BREF: World Health Organization Quality of Life Brief

\section{Introduction}

Unprecedented scientific development in recent decades have led to worsening of quality of life (QOL) due to stress, functional disorders, unrest and psychological disturbances. Professional burnout is a consequence of chronic stress seen in the work environment [1], and it is considered to be one of the components of compassion fatigue and can present itself as physical, emotional or spiritual exhaustion [2]. Some studies report the effect of the stress on the QOL in dental professionals and students leading to burnout syndrome [3-5]. In a recent report from India, high prevalence of burnout is a cause of major concern in the dental profession, affecting dentists of both genders, all ages, of different specializations and job profiles [6]. The authors had suggested that in order to combat this problem, there is a need to have balance in personal and work life and practice stress eliminating techniques like yoga and breathing techniques.
Yoga derives its origin from the Sanskrit word 'Yuj' which means to join unite or integrate it is the bringing together of body with breath and mind first and finally the union of individual consciousness with the energy that has created everything. Yoga and meditation is known to work on all aspects of a person: the physical, vital, mental, emotional, psychic and spiritual. Yoga and breathing exercises provide complete harmonization of the body and helps reduce stress and anxiety. Thus, these yoga practices in combination with meditation and relaxation techniques may be of immense benefit in dental professionals to relieve their stress and improve their QOL. This observational study was conducted to evaluate the effect of integrated approach of yoga consisting of warm-ups, loosening exercises, Asanas, Pranayama, relaxation techniques and meditation on the QOL in dental professionals at a teaching dental institution in India. 


\section{Materials and Methods}

The study was carried out at Bharati Vidyapeeth Deemed UniversityDentalCollegeand Hospital,Navi Mumbai,Maharashtra, India, which is a private dental post-graduate teaching institute affiliated to Bharati Vidyapeeth Deemed University, Pune. The study protocol and related documents were reviewed and approved by the institutional Ethics committee prior to study. Twenty dental professionals (7 male/13 female) were enrolled in the study after obtaining informed consent. All participants filled a self-administered quality of life questionnaire (WHOQOLBREF) before carrying out any study related procedures [7] and at the end of assessment period. The participants were trained for a 45-minute yoga module consisting of warm-ups (jogging, surya namaskar), loosening exercises (back twists, small joint movements), Asanas (konasana, veerbhadrasana, utkatasana, shalabhasana, bhujangasana, viparitshalabhasana, dhanurasana, pawanmuktasana, naukasana, uttancvakarasna, natarajasana, setubandhasana, body rotation, manjarasana, yogmudra, parvatasana), Pranayama (kapalbhati, nadishodhan, Bhramari, bhastrika), relaxation techniques (shavasana, yognidra) and meditation (panchakosha meditation by Sri SriRavishankar) [8]. All participants attended around 20 sessions over a 6 week and they filled the WHOQOL-BREF questionnaire to assess QOL in 5 domains (global, physical, psychological, social and environmental). The change in the QOL-BREF scores from baseline for the five domains were analyzed using Wilcoxon sign rank test. The mean change and \% change in scores for QOL-
BREF from the baseline were computed. The mean scores for total QOL-BREF scores were also compared for differences using paired ' $\mathrm{t}$ ' test.

\section{Results}

Table 1: Profile of participants.

\begin{tabular}{|c|c|c|}
\hline \multirow{2}{*}{ Age (yrs.) } & Mean $(\mathbf{n = 2 0})$ & SD \\
\cline { 2 - 3 } & 39.45 & 7.18 \\
\hline Male / Female & No. & $\%$ \\
\hline Hypertension & $13-J u l$ & $38.9 \% / 72.2 \%$ \\
\hline Diabetes mellitus & 4 & $22.20 \%$ \\
\hline Migraine & 3 & $16.70 \%$ \\
\hline Low back pain & 1 & $5.50 \%$ \\
\hline Hypothyroidism & 1 & $44.40 \%$ \\
\hline Osteoarthritis & 2 & $5.50 \%$ \\
\hline Plantar fasciitis & 1 & $11.10 \%$ \\
\hline Obesity & 4 & $5.50 \%$ \\
\hline
\end{tabular}

Of the twenty participants, two could not complete 6-week course of yoga and were excluded from analysis. Thus, data for 18 participants was evaluated. Table 1 shows the demography and disease profile of the dental professionals who participated in the study. The mean age was about 40 years with majority of them being women. The most common associated comorbid conditions were low back pain, obesity, hypertension, diabetes mellitus and osteoarthritis.

Table 2: WHOQOL-BREF scores before and after 6-week yoga course.

\begin{tabular}{|c|c|c|c|c|}
\hline & Before Yoga & After Yoga & Change & Wilcoxon Test \\
\hline & $(\mathrm{N}=18)$ & $(\mathrm{N}=18)$ & Mean (95\% C.I.) & $\mathrm{Z}(\mathrm{p})$ \\
\hline \multicolumn{5}{|c|}{ Domains } \\
\hline Global & $3.70(0.18)$ & $4.05(0.09)$ & $-0.35(-0.70$ to 0.001$)$ & $2.101(0.049)$ \\
\hline Physical & $25.60(0.73)$ & $27.45(0.75)$ & $-1.85(-2.86$ to -0.84$)$ & $3.832(0.001)$ \\
\hline Psychological & $20.35(0.59)$ & $20.60(0.63)$ & $-0.25(-1.50$ to 1.00$)$ & $0.418(0.680)$ \\
\hline Social Domain & $32.15(0.85)$ & $32.40(0.82)$ & $-0.25(-1.56$ to 1.06$)$ & $0.401(0.693)$ \\
\hline Environmental & $27.85(0.99)$ & $28.80(1.05)$ & $-0.95(-2.32$ to 0.42$)$ & $1.451(0.163)$ \\
\hline Total Score & $89.30(2.37)$ & $92.70(2.38)$ & $-3.40(-6.40$ to -0.40$)$ & $2.375(0.028)$ \\
\hline
\end{tabular}

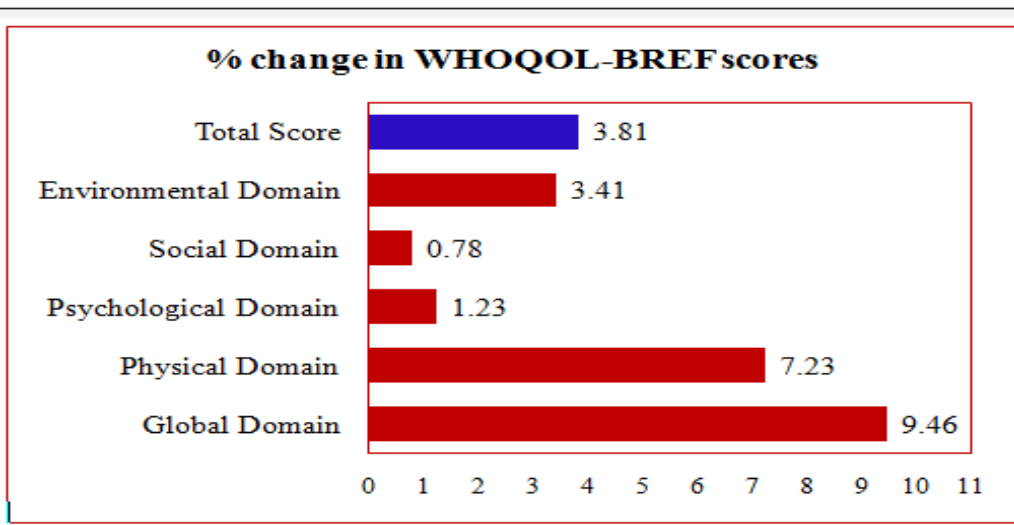

Figure 1: \% change in the WHOQOL-BREF scores after 18 weeks of yoga. 
Table 2 shows the WHOQOL-BREF scores for the different domains and the total scores before and after yoga session. After 6 weeks, there was improvement in global domain $(\mathrm{Z}=2.101$, $\mathrm{p}=0.049$, N.S. $)$, physical domain $(\mathrm{Z}=3.832, \mathrm{p}=0.001$, Sig. $)$, psychological domain $(\mathrm{Z}=0.418, \mathrm{p}=0.680$, N.S.), social domain $(\mathrm{Z}=0.401, \mathrm{p}=0.693, \mathrm{~N} . \mathrm{S}$.$) , and environmental domain (\mathrm{Z}=1.451$, $\mathrm{p}=0.163$, N.S.). For all domains pooled together there was a significant improvement from baseline $(\mathrm{Z}=2.375, \mathrm{p}=0.028$, Sig. $)$. Also, mean WHOQOL-BREF score increased significantly from 89.30 to 92.70 after 20 sessions of yoga $(p<0.05$, t-test). Figure 1 shows the percent reduction in the WHOQOL-BREEF scores after yoga sessions. Yoga sessions improved the WHOQOL-BREF scores by $3.81 \%$ from the baseline and highest improvement was observed in the global domain (9.46\%) and physical domain (7.23\%).

\section{Discussion}

Chronic stress in the work environment is one of the leading factors for burnout syndrome and could have a deleterious effect on health. Burnout resulting from chronic stress is a psychological and physical response which may arise when the employees are exposed to a stressful working environment involving elevated expectations, inadequate resources, and low compensation. This can be seen when people fail to control the work-related stress effectively. A recent study conducted to assess the prevalence of burnout among dental professionals using the abbreviated Maslach Burnout Inventory (aMBI) and Burnout Clinical Subtype Questionnaire (BCSQ-12) reported very high burnout rates in all domains of aMBI and BCSQ-12 scales among all socio-demographic and occupational categories of dentists. Amongst the dentists, 47.22\% ( $n=187)$ scored high on emotional exhaustion, $67.68 \%(n=268)$ had high scores for depersonalisation scales respectively, and 84.09\% ( $\mathrm{n}=333)$ had low personal accomplishment scale. The authors strongly recommend immediate actions to reduce burnout and stress in dental professionals. Similar observations are reported in another study among medical practitioners across India [5]. Similar reports of burnout due to work stress in healthcare professionals is reported across the world [9-12].

In spite of high levels of professional stress, little evidence exists about how to address this problem and most of the available literature focuses on individual interventions emphasize on various stress reduction techniques [13]. Yoga has been widely practised in India and other countries worldwide for healthy living and tranquillity. During stress, the mind is heavily loaded with thoughts that are rushing with enormous speed. It is this excessive speed of flow of thoughts in the mind that is called as stress. If one learns to slow down the rate of flow and become a master of this speed one has learnt to manage stress in the most efficient way. Various techniques have been advised to reduce stress like 'Alternate Nostril Breathing Technique' or also called as the 'NadiShodhan Pranayama', Bhramari Pranayam (Bee breath) [6], and Panchakosha meditation (conscious relaxation)
[14]. Yoga has shown to improve the QOL in women with pelvic pain [15], patients with osteoarthritis [16], psychiatric disorders $[17,18]$, Parkinson's disease [19], chronic low back pain [20], chronic kidney disease (CKD) [21], and also in opioid addicts [22]. Bhramari pranayama, a type of yogic breathing technique and chanting of the word 'om' has shown beneficial effects on the pulmonary function in healthy individuals $[23,24]$.

Our study observed the effects of integrated sessions of yoga and breathing techniques in improving the quality of life in dental professionals. A significant improvement was observed over a 6-week period with regular sessions. Yogic techniques include unique breathing methods which harmonizes the body, mind and emotions thus helping eliminates stress and fatigue. Our study is subject to several limitations like a small scale of sample and an observational, non-comparative study design. Hence, the results cannot be generalized to general population. However, the results suggest a high impact of Yoga and breathing techniques on the QOL of professionals.

\section{Conclusion}

Integrated approach of yoga at workplace improves QOL in Dental surgeons especially in physical domain. Studies with larger samples are needed to substantiate these benefits.

\section{References}

1. Maslach C, Schaufeli WB, Leiter MP (2001) Job burnout. Annu Rev Psychol 52: 397-342.

2. Pfifferling, John H, Gilley K (2000) Family practice management. American Academy of Family Physicians, p. 7.

3. Divaris K, Polychronopoulou A, Taoufik K, Katsaros C, Eliades T (2012) Stress and burnout in postgraduate dental education. Eur J Dent Educ 16(1): 35-42.

4. Te Brake H, Bouman AM, Gorter R, Hoogstraten J, Eijkman M (2007) Professional burnout and work engagement among dentists. Eur J Oral Sci 115(3): 180-185.

5. Langade D, Modi PD, Sidhwa YF, Hishikar NA, Gharpure AS, et al. (2016) Burnout syndrome among medical practitioners across india: a questionnaire-based survey. Cureus 8(9): e771.

6. Saxena S, Chandiramani K, Bhargava R (1998) WHOQOL-Hindi: a questionnaire for assessing quality of life in health care settings in india. World Health Organization Quality of Life. Natl Med J India 11(4): 160-165.

7. Rahul R, Pranav M, Yazad S, Namita H (2016) Burnout among dental professionals in India : a questionnaire based survey. Journal of Indian Dental Asociation 10(12): 16-25.

8. Ravishankar HHSS (2017) Bhramari pranayama-bee breathing technique: art of living india. Art of Living.

9. Sabbah I, Hala S, Sanaa S, Hussein A, Nabil D (2012) Burnout among lebanese nurses: psychometric properties of the maslach burnout inventory-human services survey (MBI-HSS). Health 4(9): 644-652.

10. Puffer JC, Knight HC, O'Neill TR, Rassolian M, Bazemore AW, et al. (2017) Prevalence of burnout in board certified family physicians. J Am Board Fam Med 30(2): 125-126.

11. Pöhlmann K, Jonas I, Ruf S, Harzer W (2005) Stress, burnout and health in the clinical period of dental education. Eur J Dent Educ 9(2): 78-84. 
12. McCue JD, Sachs CL (1991) A Stress management workshop improves residents' coping skills. Arch Intern Med 151(11): 2273-2277.

13. Ravishankar HHSS (2017b) Pancha kosha meditation-five sheaths meditation (annamaya, manomaya, vijnanamaya, pranamaya, anandamaya kosha): the art of living United Kingdom. Art of Living.

14. Saxena R, Gupta M, Shankar N, Jain S, Saxena A (2017) Effects of yogic intervention on pain scores and quality of life in females with chronic pelvic pain. Int J Yoga 10(1): 9-15.

15. Ebnezar J, Nagarathna R, Bali Y, Nagendra HR (2011) Effect of an integrated approach of yoga therapy on quality of life in osteoarthritis of the knee joint: a randomized control study. Int J Yoga 4(2): 55-63.

16. Satish L, Lakshmi VS (2016) Impact of individualized yoga therapy on perceived quality of life performance on cognitive tasks and depression among type ii diabetic patients. Int J Yoga 9(2): 130-136.

17. Ramanathan M, Bhavanani AB, Trakroo M (2017) Effect of a 12-week yoga therapy program on mental health status in elderly women inmates of a hospice. Int J Yoga 10(1): 24-28.

18. Sharma NK, Robbins K, Wagner K, Colgrove YM (2015) A Randomized controlled pilot study of the therapeutic effects of yoga in people with parkinson's disease. Int J Yoga 8(1): 74-79.

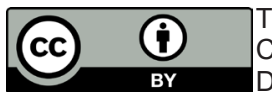

This work is licensed under Creative Commons Attribution 4.0 License

DOI: 10.19080/JYP.2017.02.555588
19. Tekur P, Chametcha S, Hongasandra RN, Raghuram N (2010) Effect of yoga on quality of life of clbp patients: a randomized control study. Int J Yoga 3(1): 10-17.

20. Pandey RK, Arya TV, Kumar A, Yadav A (2017) Effects of 6 months yoga program on renal functions and quality of life in patients suffering from chronic kidney disease. Int J Yoga 10(1): 3-8.

21. Dhawan A, Chopra A, Jain R, Yadav D, Vedamurthachar (2015) Effectiveness of yogic breathing intervention on quality of life of opioid dependent users. Int J Yoga 8(2): 144-147.

22. Prasad Sahu K, Kishore Yadav K (2015) The Effect of bhramari pranayama and jyoti dhyan effect on alpha eeg and hemoglobin of college going students. International Journal of Physical Education, Sports and Health IJPESH 1(14): 40-44.

23. Shanafelt TD, Boone S, Tan L, Dyrbye LN, Sotile W, et al. (2012) Burnout and satisfaction with work-life balance among US physicians relative to the general US population. Arch Intern Med 172(18): 1377-1385.

24. Ravishankar HHSS (2017c) The Art of Living | Yoga | Meditation | Sudarshan Kriya. Art of Living.

Your next submission with Juniper Publishers will reach you the below assets

- Quality Editorial service

- Swift Peer Review

- Reprints availability

- E-prints Service

- Manuscript Podcast for convenient understanding

- Global attainment for your research

- Manuscript accessibility in different formats

( Pdf, E-pub, Full Text, Audio)

- Unceasing customer service

Track the below URL for one-step submission https://juniperpublishers.com/online-submission.php 